\title{
Simplified Acid Treatment Technique in Cobalt-Chromium Alloys: Effect on Metal-Ceramic Bond Strength
}

\author{
Michelli Menezes Sobreiro ${ }^{a}$, Ana Paula Macedo ${ }^{a *}$ (D), Osvaldo Luiz Bezzon \\ Valéria Oliveira Pagnano ${ }^{a}$ (D) \\ ${ }^{a}$ Universidade de São Paulo (USP), Faculdade de Odontologia de Ribeirão Preto, Departamento de
Materiais Dentários e Prótese Dentária, Ribeirão Preto, SP, Brasil.
}

Received: May 24, 2021; Revised: August 16, 2021; Accepted: September 19, 2021.

\begin{abstract}
This study aim was to evaluate the influence of $37 \%$ hydrochloric acid $(37 \% \mathrm{HCl})$ treatment of cobalt-chromium (Co-Cr) alloys on the metal-ceramic bond strength (MCBS). The specimens were sandblasted with $100-\mu \mathrm{m}$ aluminum oxide particles and divided into four groups $(\mathrm{n}=10)$ according to the surface treatment performed: control (C) - no treatment - and treated with $37 \% \mathrm{HCl}$ for different times: 10 minutes (T1), 20 minutes (T2) and 30 minutes (T3). The samples were submitted to the 3 -point bending test, and the type of failure was evaluated. Wald, Bonferroni and Pearson's tests were applied $(\alpha=0.05)$. There was difference between the treatments $(\mathrm{p}=0.019)$ : T3 $(61.57 \mathrm{MPa})$ had higher bond strength than $\mathrm{C}(51.96 \mathrm{MPa})$. The specimens presented $17.5 \%$ of adhesive and $82.5 \%$ of mixed failures. There was a weak correlation between the failure type and the MCBS. Co-Cr surface treatment with $37 \% \mathrm{HCl}$ for 30 minutes is a promising protocol for an appropriate metal-ceramic bond strength.
\end{abstract}

Keywords: Dental alloys, Dental ceramics, Hydrochloric acid.

\section{Introduction}

Metal-ceramic restorations have acceptable clinical performance, longevity ${ }^{1}$, and physical properties ${ }^{2}$. However, their clinical success depends on a number of factors, including the properties of the alloy ${ }^{2}$, adequate marginal fit, and adequate metal-ceramic bond strength ${ }^{3}$. Cobalt-chromium alloys (Co-Cr) characteristics, such as biocompatibility ${ }^{4}$, marginal integrity ${ }^{5}$, high strength during ceramic firing, high modulus of elasticity, and low $\operatorname{cost}^{6,7}$, justify their current use in metal-ceramic fixed prosthesis frameworks and in Implantology $\mathrm{y}^{8,9}$.

The bond between metal and ceramic occurs during the sintering process, and may be of physical, mechanical and / or chemical nature ${ }^{10}$. Physical bond is provided by the van der Waals forces, which have little contribution to metal-ceramic bond strength (MCBS) ${ }^{11}$. Mechanical bonding is related to compressive forces from the difference in the coefficients of thermal expansion of metal and ceramics ${ }^{10}$, or to the surface roughness and retentive edges in the metal structure, which may favor wettability ${ }^{12}$. Chemical bond occurs when the elements of dental alloys, such as cobalt, chromium, and molybdenum ${ }^{13}$, undergo surface oxidation forming ion channels, where the diffusion of atoms present in metal-ceramic interface occurs ${ }^{13}$. The composition and morphology of this oxide layer depends on the type of surface treatment performed ${ }^{14}$ as well as interaction among atoms from both metal and ceramic ${ }^{12}$, which may interfere in $\mathrm{MCBS}^{13-15}$. If the thickness of this film reduces in the sintering process, the MCBS decreases ${ }^{3}$. If the layer formed of $\mathrm{Cr}_{2} \mathrm{O}_{3}$ is compact ${ }^{16}$, there is reduced bond strength on this

*e-mail: anapaula@forp.usp.br interface. In addition, a layer that is too thick with an excess of chromium oxides promotes the reduction of the ceramic thermal expansion coefficient ${ }^{17}$, favoring the reduction of the ceramic cohesive resistance ${ }^{18,19}$, which can result in failure of the restoration when submitted to chewing forces ${ }^{20}$.

For this reason, $\mathrm{Co}-\mathrm{Cr}$ alloy manufacturers usually recommend the use of a bonding agent ${ }^{13}$ to improve the chemical affinity between metal and ceramic.

Since this oxide layer greatly influences the $\mathrm{MCBS}^{3}$, there is a constant search for the improvement of laboratory and clinical techniques to maximize the maintenance of prosthetic restorations in the oral cavity. However, imperfections, such as mechanical failures ${ }^{18-20}$, incompatibility of selected materials, inappropriate ceramic application technique, incorrect thickness of the metal structure, can still occur and lead to loss of the prosthesis ${ }^{20,21}$.

In this context, various surface treatments have been proposed to increase wettability of the metal, but despite presenting promising results, the techniques used in these studies are difficult to apply and reproduce in dental laboratories. For example, the $100-\mu \mathrm{m}$ aluminum oxide $\left(\mathrm{Al}_{2} \mathrm{O}_{3}\right)$ sandblasting ${ }^{12,17,22,23}$ requires a positioning device for sandblasting at specific angles and distances. In addition, other variables, such as the time and the pressure of the sandblasting application and the size of the aluminum oxide particles can affect the final results.

Another treatment described is the use of a bonding agent $^{12,24}$, which has a higher cost and the applied layer thickness is difficult to standardize, interfering with $\mathrm{MCBS}^{12,15}$. Moreover, some proposed protocols require materials that are difficult to access, such as oxidation heat treatment ${ }^{23,25}$, 
which requires specific gases for the sintering process, or chemical treatment of both noble and titanium alloys to create microporosities and remove contaminants from the metal surface $12,15,22,26,27$.

Acid etching can also be used on metal surfaces to improve the MCBS. Different concentrations of hydrochloric $(\mathrm{HCl})$, sulfuric $\left(\mathrm{H}_{2} \mathrm{SO}_{4}\right)$, nitric $\left(\mathrm{HNO}_{3}\right)$ and/or hydrofluoric $(\mathrm{HF})$ acid solutions are proposed, however, there are discrepancies in the literature regarding its effectiveness ${ }^{12,14,15,26,27}$, demonstrating the need for more studies of this type of surface treatment.

There is a lack of standardized protocols in the literature regarding the $\mathrm{Co}-\mathrm{Cr}$ surface treatment and a need to minimize prosthetic failures in the clinical practice. Thus, the aim of this study was to establish a simple protocol with materials of easy access and low cost by assessing the effect of $37 \%$ $\mathrm{HCl}$ acid etching on MCBS of three Co-Cr alloys. The null hypothesis was that there would be no difference in the MCBS due to surface treatments and no correlation between the type of failure and the MCBS.

\section{Material and Method}

\subsection{Sample preparation}

One hundred and twenty specimens of three Co-Cr alloys (Table 1) were made with the dimensions of $25 \times 3.0 \times 0.5 \mathrm{~mm}$ (ISO 9693:2012) ${ }^{28}$ using a Teflon matrix (Figure 1). Duralay acrylic resin (Reliance Dental Mfg Co. Worth, EUA) was mixed according to the manufacturer's specifications and deposited in part " $A$ " of the die and pressed into part " $D$ ". Resin patterns were invested in Micro Fine 1700 phosphate coating (Talladium Inc., California, USA), cast in Neutrodyn Easyti electronic machine (F.Lli Manfredi, Piedmont, Italy), and sandblasted with $100 \mu \mathrm{m}$ aluminum oxide particles (Renfert, Gmbh; Hilzingen, Germany) under 3 bar pressure.

The 40 specimens of each $\mathrm{Co}-\mathrm{Cr}$ alloy were made and randomized (Excel; Microsoft Corp) distributed into the 4 groups $(n=10)$ to receive one of the proposed surface treatments (Table 2). The excess acid was removed from the distilled water drip, followed by abundant washing in running water for one minute. All samples were cleaned in an ultrasonic bath (Odontobrás, Ribeirão Preto, SP, Brazil) with isopropyl alcohol for 10 minutes. Ceramic (Ivoclar VivaDent, Amherst, NY, USA) was applied to the central portion of the samples $(8.0 \mathrm{~mm} \times 3.0 \mathrm{~mm} \times 1.0 \mathrm{~mm})$ with the aid of the Teflon matrix. All samples received two opaque and two dentin ceramic layers; sintering cycles were performed under vacuum in an Alumini sintering press
(EDG Equipamentos, São Paulo, SP, Brazil) according to the manufacturer's specifications.

\subsection{Bond strength test}

The specimens were subjected to a three-point bending test on a DL 2000 (EMIC, São José dos Pinhais, Paraná, Brazil) mechanical testing machine at a speed of $1.0 \mathrm{~mm} /$ $\min (5 \mathrm{kgf})$ until the metal-ceramic debonding strength.

The sample size for the metal-ceramic bond strength was based on the study of Farzin et al. ${ }^{29}$, that showed a minimally significant difference of 8.23 and a standard deviation of 6.02 , which led to $n=9$ /group to ensure a power of $80 \%(\alpha=0.05 ; \beta=0.2)$. However, the sample size was increased to 10 , consistent with that of previous study by the research group ${ }^{30}$.

The final values of the failure stress $(\mathrm{MPa})$ were obtained by applying the formula: $\mathrm{T}=\mathrm{k} \cdot \mathrm{F}$, where $\mathrm{T}$ is the tensile strength in $\mathrm{MPa}, \mathrm{k}$ is the alloy constant value in $\mathrm{mm}^{2}$, which is a function of thickness $(\mathrm{dM}=0.5 \pm 0.05 \mathrm{~mm})$ and the modulus of elasticity (ME) of the metal substrate, and $\mathrm{F}$ is the value of the maximum force in Newtons $(\mathrm{N})$ (ISO 9693:2012) $)^{28}$.

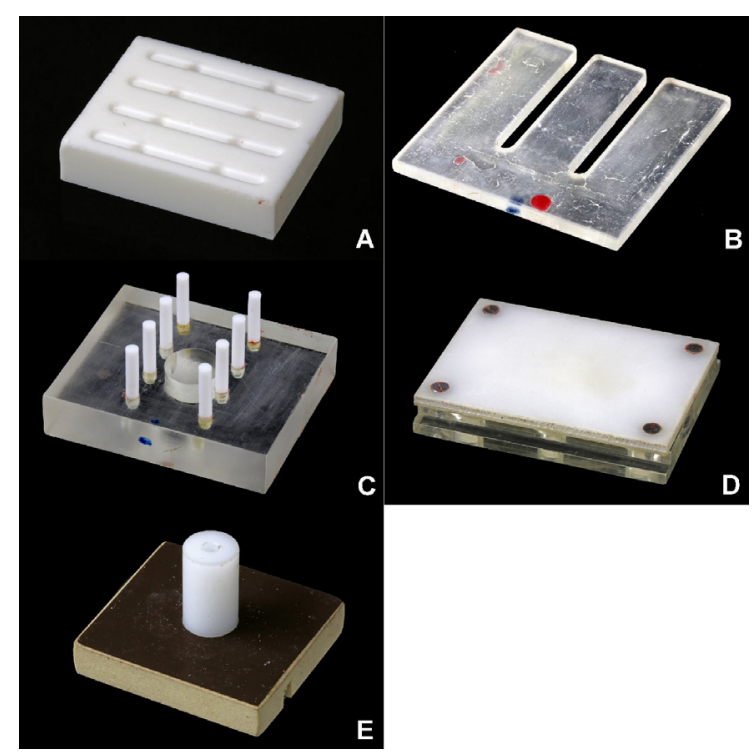

Figure 1. Teflon matrix for obtaining the acrylic resin standards: A - Upper part; B - $0.7 \mathrm{~mm}$ spacer; C - Spacer positioning device; $\mathrm{D}$ - Acrylic resin pressing base; E - Lower part.

Table 1. Characteristics of $\mathrm{Co}-\mathrm{Cr}$ dental alloys evaluated.

\begin{tabular}{|c|c|c|c|c|c|}
\hline Co-Cr alloys & $\begin{array}{c}\text { Composition } \\
(\% \text { in large scale })\end{array}$ & $\begin{array}{c}\text { Modulus of } \\
\text { elasticity }(\mathrm{GPa})\end{array}$ & Manufacturer & Batch & $\begin{array}{c}\text { Casting } \\
\text { Temperature }\end{array}$ \\
\hline Keragen & $\begin{array}{c}\text { Co } 61 ; \operatorname{Cr} 28 ; \mathrm{W} 8.5 ; \\
\text { Si } 1.65 ; \operatorname{Mn} 0.25 ; \mathrm{Fe}<0.5 \\
C<0.1\end{array}$ & 150 & $\begin{array}{c}\text { Eisenbacher, Dentalwaren } \\
\text { ED GmbH, Alemanha }\end{array}$ & F03-500sk & $1410^{\circ} \mathrm{C}$ \\
\hline Remanium 2001 & $\begin{array}{c}\text { Co 63; Cr 23; Mo 7.3; } \\
\text { W 4.3; Si } 1\end{array}$ & 195 & $\begin{array}{c}\text { Dentaurum, Pforzheim, } \\
\text { Alemanha }\end{array}$ & 102-600-01 & $1390^{\circ} \mathrm{C}$ \\
\hline StarLoy C & $\begin{array}{c}\text { Co 59.4; Cr 24.5; W 10; } \\
\text { Nb 2.2; V 2.2; Si } 1 ; \\
\text { Mo } 1 ; \text { Fe } 1\end{array}$ & 200 & $\begin{array}{c}\text { DeguDent GmbH, Hanau, } \\
\text { Alemanha }\end{array}$ & 35010014 & $1370^{\circ} \mathrm{C}$ \\
\hline
\end{tabular}




\subsection{Failure assessment}

After testing, the specimens were observed under the Nikon SMZ800 Stereo Magnifying Glass (Nikon Corporation) and failures were classified as: adhesive (failure between the metal oxide layer and the opaque ceramic), cohesive (internal failure in the ceramic layer), or mixed (cohesive + adhesive $)^{16,21,31,32}$.

\subsection{Statistical analysis}

Statistical analysis was performed using the SPSS software (IBM) with a statistical significance level of 0.05 . Data were tested for normality (Shapiro Wilk) and homoscedasticity (Levene). Homogeneity of variation was not observed and data were compared with Wald test in Generalized Linear Model and Bonferroni post-test. To compare failures among the groups, the Pearson Chi-Square test was used. The correlation between the bond strength and the type of failure was assessed with the Pearson test, and for the correlation between type of failure and surface treatment, the Spearman test was used.

\section{Results}

Significant differences were found between the treatments $(\mathrm{W}=9.96 ; \mathrm{p}=0.019): \mathrm{T} 3(61.57 \mathrm{MPa})$ had higher bond strength than C (51.96 MPa). The groups T1 (57.82 MPa) and T2 (57.91 MPa) had intermediate value, with no significant difference when compared to $\mathrm{C}$ and $\mathrm{T} 3$. There was no difference among the alloys used $(\mathrm{W}=4.97 ; \mathrm{p}=0.083)$ and no interaction between the alloys and the treatments $(\mathrm{W}=10.79 ; \mathrm{p}=0.095)$. The descriptive statistics of the tensile stress is presented in Table 3 .

No specimen presented cohesive failure in the ceramic layer (Table 4). No difference was found in the proportion of adhesive (Figure 2A) and mixed (Figure 2B) failures for the different treatments in each of the evaluated alloys (Keragen $-\mathrm{p}=0.473 ;$ Remanium $-\mathrm{p}=0.222 ;$ Starloy $\mathrm{C}-\mathrm{p}=0.227$ ).

For the acid-treated groups there was no difference in the proportion of adhesive and mixed failures among the alloys in the evaluated times $(10 \mathrm{~min}, \mathrm{p}=1.000 ; 20 \mathrm{~min}, \mathrm{p}=0.535$; 30 min, $p=0.315)$. For the control group $(p=0.039)$, a difference was found in the proportion of type of failures, with Keragen alloy showing 100\% mixed failure, Remanium

Table 2. Surface treatments applied to Co-Cr dental alloys.

\begin{tabular}{ccccc}
\hline Groups & $\begin{array}{c}\text { Aluminum oxide blasting } \\
(100 \mu \mathrm{m}) \\
\text { (time/pressure } / \text { distance) }\end{array}$ & $\begin{array}{c}37 \% \text { Hydrochloric acid } \\
(\text { time })\end{array}$ & Distilled water (drops) & Wash in abundant water \\
\hline Control $(\mathrm{C})$ & $5 \mathrm{~s} / 3 \mathrm{bar} / 2 \mathrm{~cm}$ & - & - & 20 drops \\
\hline $\mathrm{T} 1$ & $5 \mathrm{~s} / 3 \mathrm{bar} / 2 \mathrm{~cm}$ & $10 \mathrm{~min}$ & 20 drops & $1 \mathrm{~min}$ \\
\hline $\mathrm{T} 2$ & $5 \mathrm{~s} / 3 \mathrm{bar} / 2 \mathrm{~cm}$ & $20 \mathrm{~min}$ & 20 drops & $1 \mathrm{~min}$ \\
\hline $\mathrm{T} 3$ & $5 \mathrm{~s} / 3 \mathrm{bar} / 2 \mathrm{~cm}$ & $30 \mathrm{~min}$ & & \\
\hline
\end{tabular}

Table 3. Descriptive statistics of metal-ceramic bond strength (MPa) calculated for the variation factors: alloy, surface treatment and the interaction between alloy and surface treatment.

\begin{tabular}{|c|c|c|c|}
\hline Co-Cr alloy & Treatment & Mean \pm SD (Median) & $\begin{array}{l}\text { 95\% Confidence Interval for } \\
\text { Mean (minimum; maximum) }\end{array}$ \\
\hline \multirow{5}{*}{ Keragen (K) } & $\mathrm{C}$ & $51.82 \pm 8.49(50.59)$ & $45.74 ; 57.89(42.23 ; 65.47)$ \\
\hline & $\mathrm{T} 1$ & $55.49 \pm 8.63(57.19)$ & $49.31 ; 61.66(35.61 ; 64.85)$ \\
\hline & $\mathrm{T} 2$ & $62.55 \pm 14.01(66.72)$ & $52.53 ; 72.57(42.01 ; 77.69)$ \\
\hline & T3 & $66.75 \pm 12.70(64.64)$ & $57.67 ; 75.84(47.70 ; 94.14)$ \\
\hline & Total $(\mathrm{K})$ & $59.15 \pm 12.30(58.47)$ & $55.22 ; 63.09(35.61 ; 94.14)$ \\
\hline \multirow{5}{*}{ Remanium 2001 (R) } & $\mathrm{C}$ & $53.44 \pm 20.74(48.62)$ & $38.60 ; 68.28(14.16 ; 93.86)$ \\
\hline & $\mathrm{T} 1$ & $66.94 \pm 17.13(68.66)$ & $54.69 ; 79.20(37.90 ; 99.35)$ \\
\hline & $\mathrm{T} 2$ & $57.77 \pm 4.66(57.81)$ & $54.43 ; 61.10(48.75 ; 65.67)$ \\
\hline & T3 & $57.53 \pm 12.57(56.23)$ & $48.53 ; 66.52(44.12 ; 79.67)$ \\
\hline & Total $(\mathrm{R})$ & $58.92 \pm 15.28(57.77)$ & $54.03 ; 63.81(14.16 ; 99.35)$ \\
\hline \multirow{5}{*}{ StarLoy C (S) } & $\mathrm{C}$ & $50.64 \pm 9.19(49.69)$ & $44.07 ; 57.21(37.70 ; 66.50)$ \\
\hline & T1 & $51.03 \pm 6.79(51.03)$ & $46.17 ; 55.89(40.87 ; 63.83)$ \\
\hline & $\mathrm{T} 2$ & $53.42 \pm 7.98(55.08)$ & $47.71 ; 59.13(39.89 ; 66.20)$ \\
\hline & T3 & $60.43 \pm 10.51(63.17)$ & $52.91 ; 67.95(47.51 ; 74.49)$ \\
\hline & Total (S) & $53.88 \pm 9.28(53.17)$ & $50.91 ; 56.85(37.70 ; 74.49)$ \\
\hline \multirow{4}{*}{ Total (Treatment)* } & $\mathrm{C}^{\mathrm{a}}$ & $51.96 \pm 13.54(49.21)$ & $46.91 ; 57.02(14.16 ; 93.86)$ \\
\hline & $\mathrm{T} 1^{\mathrm{ab}}$ & $57.82 \pm 13.23(55.83)$ & $52.88 ; 62.76(35.61 ; 99.35)$ \\
\hline & $\mathrm{T} 2^{\mathrm{ab}}$ & $57.91 \pm 10.09(57.77)$ & $54.15 ; 61.68(39.89 ; 77.69)$ \\
\hline & $\mathrm{T}^{\mathrm{b}}$ & $61.57 \pm 12.20(61.85)$ & $57.02 ; 66.13(44.12 ; 94.14)$ \\
\hline
\end{tabular}

* Multiple comparisons with Bonferroni adjustment; ab equal letters indicate statistical similarity; C- control; T1 - treatment with HCl-37\% for 10 min; $\mathrm{T} 2$ - HCl-37\% treatment for $20 \mathrm{~min}$; $\mathrm{T} 3-\mathrm{HCl}-37 \%$ treatment for $30 \mathrm{~min}$. 
Table 4. Distribution of the type of failures found in all treatments performed on Co-Cr surfaces.

\begin{tabular}{|c|c|c|c|c|c|c|c|c|}
\hline \multirow{2}{*}{ Treatment } & \multicolumn{2}{|c|}{ Keragen } & \multicolumn{2}{|c|}{ Remanium 2001} & \multicolumn{2}{|c|}{ StarLoy C } & \multicolumn{2}{|c|}{ Total (treatment) } \\
\hline & Adhesive & Mixed & Adhesive & Mixed & Adhesive & Mixed & Adhesive & Mixed \\
\hline $\mathrm{C}$ & 0 & 10 & 5 & 5 & 3 & 7 & 8 & 22 \\
\hline $\mathrm{T} 1$ & 1 & 9 & 1 & 9 & 1 & 9 & 3 & 27 \\
\hline $\mathrm{T} 2$ & 2 & 8 & 3 & 7 & 1 & 9 & 6 & 24 \\
\hline $\mathrm{T} 3$ & 2 & 8 & 2 & 8 & 0 & 10 & 4 & 26 \\
\hline Total (alloy) & 5 & 35 & 11 & 29 & 5 & 35 & 21 & 99 \\
\hline
\end{tabular}

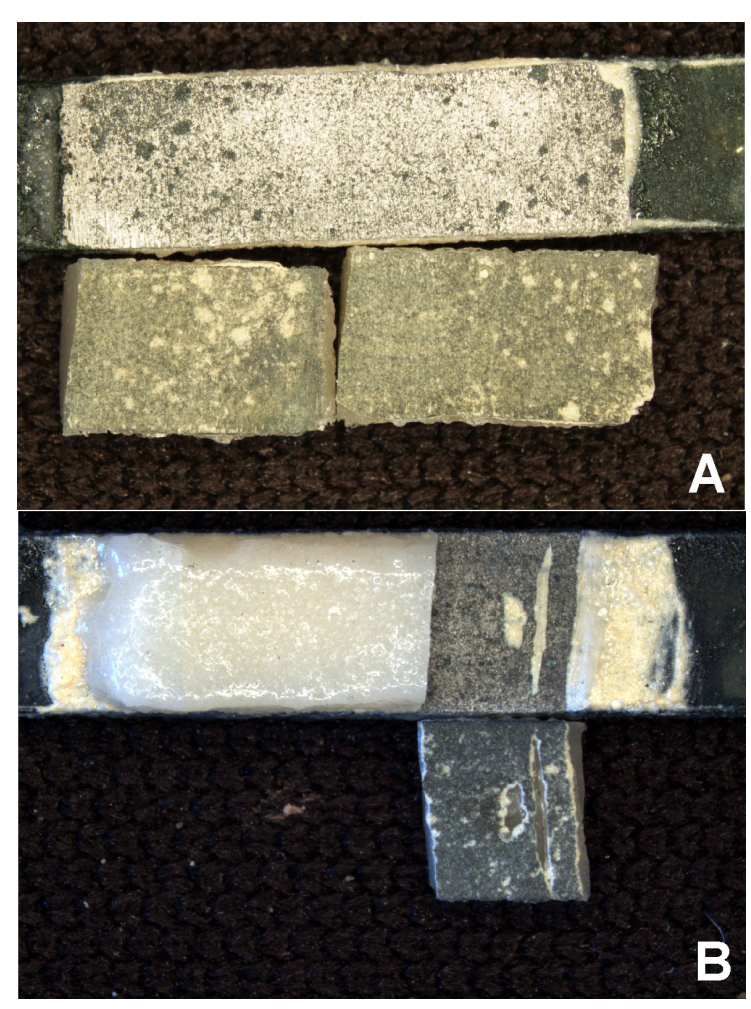

Figure 2. Type of failure: A - Adhesive failure; B - Mixed failure.

$50 \%$ mixed failure and 50\% adhesive failure and StarLoy C presenting $30 \%$ adhesive failure and $70 \%$ of mixed failures.

A poor correlation was found between the type of failure $(\rho=0.199)$ and the MCBS $(p=0.03)$; a prevalence of mixed failures was observed in specimens with higher bond strength. There was no correlation between the surface treatment and the type of failure $(\rho=0.088 ; p=0.338)$.

\section{Discussion}

This study aimed to investigate the effect of Co-Cr alloy surface treatment with $37 \% \mathrm{HCl}$ for different exposure times on the MCBS. The null hypothesis was rejected, since acid treatment for 30 minutes increased the MCBS, regardless of the alloy used, with a weak correlation between the type of failure and the MCBS.

Acid treatment for 30 minutes generated significant increase (18\%) in the MCBS compared to the control. These results corroborate the findings of Reyes et al. ${ }^{12}$, who found that heated $10 \% \mathrm{HCl}$ applied for 30 minutes in titanium surfaces resulted in greater MCBS than the other groups analyzed (polished surface, sandblasting with aluminum oxide particles, treatment with aqueous $\mathrm{HCl}$ solution and nitric acid with or without sandblasting, sulfuric acid, and hydrogen peroxide). According to the authors, sandblasting with $50 \mu \mathrm{m}$ aluminum oxide particles contaminated the metal surface and modified the surface profile, leading to a weak metal-ceramic bond, while the acid treatment provided surface roughness and a contact angle that favored wettability, increasing the $\mathrm{MCBS}$. In addition, $\mathrm{HCl}$ treatment reduced the oxide layer on the titanium surface, reducing the formation of metal oxides and increasing MCBS. However, our results differed from the finding of Lee et al. ${ }^{26}$ who also compared titanium surface treatment with heated $10 \% \mathrm{HCl}$ for 30 minutes and sandblasting with 50 and $250 \mu \mathrm{m}$ aluminum oxide particles, and found higher values of metal-ceramic bond strength for the sandblasted groups.

We found that for $\mathrm{Co}-\mathrm{Cr}$ alloys the increase in acid concentration from 10 to $37 \%$ provided a significant improvement in MCBS without heating the solution ${ }^{12,26}$, simplifying and standardizing the technique, which favors its use by prosthetic technicians. In addition, the $37 \%$ hydrochloric acid is commercially available and can be applied at room temperature, which allows the reproducibility of the technique, avoiding contradictory results such as those described by Reyes et al. ${ }^{12}$ and Lee et al. ${ }^{26}$, neither of which mention the temperature of acid heating, making the proposed protocols impossible to reproduce.

The MCBS depends on micro mechanical grip between the substrates and the control of oxide layer formation at the interface ${ }^{13}$. The treatment with $37 \% \mathrm{HCl}$ may have contributed with either or both aspects, since shorter application times also improved, although not significantly, bond strength compared to control (10 min, 11.3\% and $20 \mathrm{~min}, 11.4 \%$ ).

The MCBS was assessed by the three-point bending test according to the criteria of ISO 9693: $2012^{28}$, which establishes $25 \mathrm{MPa}$ as the minimum acceptable value for breaking stress. In the present study, all specimens evaluated had values greater than $25 \mathrm{MPa}$, and were thus clinically acceptable. However, the group T3 had $18.4 \%$ higher mean $(61.57 \mathrm{MPa})$ than group $\mathrm{C}(51.96 \mathrm{MPa})$, which added with easy handling technique and low cost, justifies the use of the proposed acid treatment. The three-point bonding test was selected because it provides data that is more reliable, as it considers the thickness and modulus of elasticity of the alloy and provides tensile and shear forces ${ }^{32}$. Thus, it is the most suitable test to evaluate bond strength ${ }^{12,23,26,33,34}$.

Surface treatments were performed on three $\mathrm{Co}-\mathrm{Cr}$ alloys that have different modulus of elasticity and chemical 
compositions (Table 1). The chemical composition can affect MCBS by affecting the formation of the oxide layer or the coefficient of thermal expansion ${ }^{8}$. Keragen was the only evaluated alloy that had no molybdenum in its composition, an element that is added to decrease the coefficient of thermal expansion and increase corrosion resistance ${ }^{10}$. However, all three alloys evaluated had similar bond strength, suggesting that treatment with $37 \% \mathrm{HCl}$ for 30 minutes might be effective regardless of the Co-Cr alloy used. On the contrary, Joias et al. ${ }^{3}$, when comparing the bond strength among five $\mathrm{Co}-\mathrm{Cr}$ alloys and one $\mathrm{Au}-\mathrm{Pd}$ alloy, found differences in both the observed failure type and the shear bond strength, attributing the difference to the distinct components of the dental alloys. However, Rathi et al. ${ }^{23}$ evaluated the MCBS of different Ni-Cr structures with different surface treatments: oxidation heat treatment; sandblasting; combination of both and did not observe a difference.

In all groups, the prevalence of mixed failures was observed, that express the best bond strength ${ }^{35}$. In this work, there was no difference in the proportion of adhesive and mixed failures among the treatments for each alloy, but the treated groups were different to the control group. Thus, it is believed that the proposed surface treatment results in better standardization of metal-ceramic adhesion, and greater predictability of clinical outcomes.

Akova et al..$^{21}$ reported different percentages of mixed and adhesive failures based on the technique for obtaining the metallic structures. In the present study, all $\mathrm{Co}-\mathrm{Cr}$ specimens were fabricated by induction casting and vacuum centrifugation, and randomly distributed to different surface treatment groups. Ekren et al. ${ }^{34}$ and Tulga ${ }^{36}$ found $100 \%$ of mixed failure between metal-ceramic structures, although they reported significant differences in bond strength among the analyzed groups, probably due to the different alloy compositions and the process for obtaining the specimens. However, the type of failure was not associated with the bond strength, similar to the results of the present study, which also found that the type of failure was poorly associated with the MCBS, and there was no significant difference in MCBS among the evaluated alloys.

In this study, $17.5 \%$ of failures were adhesive and $82.5 \%$ were mixed, while Henriques et al. ${ }^{33}$ reported $80 \%$ of adhesive and $20 \%$ of mixed failures. The different findings are probably due to the different techniques used to obtain the final specimens. Differently from this study, the authors compared the MCBS of a polished and sandblasted CoCrMoSi alloy with a low-melting feldspathic ceramic, produced by pressing under vacuum. Moreover, although there were differences in the MCBS among the alloys, there was no correlation with the type of failure.

Regardless of the technique or the type of failure found, no study reported a correlation between the type of failure and the bond strength ${ }^{21,33,34,36,37}$, differently from the present study, which found a weak correlation between the type of failure and the MCBS. The established protocol seems promising as it provided increased bond strength in $\mathrm{Co}-\mathrm{Cr}$ alloys. However, this is in vitro study, it does not replicate clinical conditions where factors such as humidity, $\mathrm{pH}$ change, and temperature are present ${ }^{13}$. In this way, further research should be conducted to analyze the influence of $37 \% \mathrm{HCl}$ on other variables, thus confirming the protocol as appropriate for $\mathrm{Co}-\mathrm{Cr}$ metal-ceramic restorations.

\section{Conclusion}

Based on the findings of this in vitro study, the following conclusions were drawn:

- The treatment of the metal surface with $37 \% \mathrm{HCl}$ for 30 minutes increased the metal-ceramic bond strength;

- There was no difference in metal-ceramic bond strength among the cobalt-chromium alloys used;

- A weak correlation was found between the type of failure and the metal-ceramic bond strength in the evaluated alloys;

- There was no correlation between the surface treatment and the type of failure.

\section{Acknowledgements}

This study was financed by the Coordenação de Aperfeiçoamento de Pessoal de Nível Superior - Brasil (CAPES) - Finance Code 001.

\section{References}

1. Behr M, Zeman F, Baitinger T, Galler J, Koller M, Handel G, et al. The clinical performance of porcelain-fused-to-metal precious alloy single crowns: chipping, recurrent caries, periodontitis, and loss of retention. Int J Prosthodont. 2014;27(2):153-60.

2. Roberts HW, Berzins DW, Moore BK, Charlton DG. Metal-ceramic alloys in dentistry: a review. J Prosthodont. 2009;18(2):188-94.

3. Joias RM, Tango RN, Araujo JEJ, Araujo MAJ, Saavedra GS, Paes-Junior TJ, et al. Shear bond strength of a ceramic to $\mathrm{Co}-\mathrm{Cr}$ alloys. J Prosthet Dent. 2008;99(1):54-9.

4. Comaneanu RM, Hancu V, Barbu HM, Coman C, Cotrut CM, Tarcolea M, et al. Comparative assessment of biocompatibility of $\mathrm{NiCr}$ and $\mathrm{CoCr}$ alloys used in metal-fused-to-ceramic technology. Rev Chimie. 2015;66(3):312-5.

5. Eliasson A, Arnelund CF, Johansson A. A clinical evaluation of cobalt-chromium metal-ceramic fixed partial dentures and crowns: a three- to seven-year retrospective study. J Prosthet Dent. 2007;98(1):6-16.

6. Wataha JC, Messer RL. Casting alloys. Dent Clin North Am. 2004;48(2):499-512.

7. Presotto AGC, Cordeiro JM, Presotto JGC, Rangel EC, da Cruz NC, Landers R, et al. Feasibility of 3D printed $\mathrm{Co}-\mathrm{Cr}$ alloy for dental prostheses applications. J Alloys Compd. 2021;862:158171.

8. Wataha JC. Alloys for prosthodontic restorations. J Prosthet Dent. 2002;87(4):351-63.

9. Bae E-J, Kim H-S, Lim JY. Evaluation of bond strength of porous cobalt-chromium metal and pressed ceramic fabricated by additive manufacturing. J Prosthet Dent. 2020;124(6):808. e1-5.

10. Anusavice KJ, Shen C, Rawls HR. Phillips' science of dental materials. 12th ed. St Louis: Elsevier; 2012. p. 69-91.

11. Juntavee N, Oeng S. Shear bond strength of ceramic fused to CAD-CAM milled alloys. J Clin Exp Dent. 2018;10(1):e32-40.

12. Reyes MJD, Oshida Y, Andres CJ, Barco T, Hovijitra S, Brown D. Titanium-porcelain system. Part III: effects of surface modification on bond strengths. Biomed Mater Eng. 2001;11(2):117-36.

13. Dimitriadis K, Papadopoulos T, Agathopoulos S. Effect of bond agent on metal-ceramic bond strength between $\mathrm{Co}-\mathrm{Cr}$ 
fabricated with selective laser melting and dental feldspathic porcelain. J Prosthodont. 2019;28(9):1029-36.

14. Park WU, Park HG, Hwang KH, Zhao J, Lee JK. Interfacial property of dental dobalt-dhromium alloys and their bonding strength with porcelains. J Nanosci Nanotechnol. 2017;17(4):2585-8.

15. Anusavice KJ, Ringle RD, Fairhurst CW. Bonding mechanism evidence in a ceramic-nonprecious alloy system. J Biomed Mater Res. 1977;11(5):701-9.

16. Zhou Y, Li N, Wang H, Yan J, Liu W, Xu S. Effects of the rare earth element lanthanum on the metal-ceramic bond strength of dental casting Co-Cr alloys. J Prosthet Dent. 2019;121(5):848-57.

17. Lombardo GHL, Nishioka RS, Souza ROA, Michida SMA, Kojima AN, Mesquita AMM, et al. Influence of surface treatment on the shear bond strength of ceramics fused to cobalt-chromium. J Prosthodont. 2010;19(2):103-11.

18. Melo RM, Travassos AC, Neisser MP. Shear bond strengths of a ceramic system to alternative metal alloys. J Prosthet Dent. 2005;93(1):64-9.

19. Antanasova M, Kocjan A, Kovač J, Žužek B, Jevnikar P. Influence of thermo-mechanical cycling on porcelain bonding to cobalt-chromium and titanium dental alloys fabricated by casting, milling, and selective laser melting. J Prosthodont Res. 2018;62(2):184-94.

20. Özcan M. Fracture reasons in ceramic-fused-to-metal restorations. J Oral Rehabil. 2003;30(3):265-9.

21. Akova T, UcarY, Tukay A, Balkaya MC, Brantley WA. Comparison of the bond strength of laser-sintered and cast base metal dental alloys to porcelain. Dent Mater. 2008;24(10):1400-4.

22. Parchańska-Kowalik M, Wołowiec-Korecka E, Klimek L. Effect of chemical surface treatment of titanium on its bond with dental ceramics. J Prosthet Dent. 2018;120(3):470-5.

23. Rathi S, Chittaranjan B, Parkash H, Bhargava A. Oxidation heat treatment affecting metal. Indian J Dent Res. 2011;22(6):877-8.

24. Minesaki Y, Murahara S, Kajihara Y, Takenouchi Y, Tanaka T, Suzuki S, et al. Effect of metal conditioner on bonding of porcelain to cobalt-chromium alloy. J Adv Prosthodont. 2016;8(1):1-8.

25. Yan X, Xu YX, Wu Y, Lin H. Effects of heat treatment on metal-ceramic combination of selective-laser-melted cobaltchromium alloy. J Prosthet Dent. 2018;120(2):319.e1-6.
26. Lee BA, Kim OS, Vang MS, Park YJ. Effect of surface treatment on bond strength of Ti-10Ta-10Nb to low-fusing porcelain. J Prosthet Dent. 2013;109(2):95-105.

27. Cai Z, Bunce N, Nunn ME, Okabe T. Porcelain adherence to dental cast $\mathrm{CP}$ titanium: effects of surface modifications. Biomaterials. 2001;22(9):979-86.

28. International Organization for Standardization - ISO. ISO 9693:2012/Amd. 1: 2012: metal: ceramic system. Geneva: ISO; 2012 .

29. Farzin M, Khaledi AA, Malekpour B, Naseri MH. Evaluation of bond strength of pressed and layered veneering ceramics to nickel-chromium alloy. J Dent. 2015;16(3):230-6.

30. Pagnano VO, Esquivel MC, Leal MB, Felipucci DN, Bezzon OL. Effect of casting atmosphere on the shear bond strength of a ceramic to Ni-Cr and Ni-Cr-Be alloys. Braz Dent J. 2009;20(2):138-42.

31. Kaleli N, Ural Ç, Kuçukekenci AS. The effect of layer thickness on the porcelain bond strength of laser-sintered metal frameworks. J Prosthet Dent. 2019;122(1):76-81.

32. Hammad IA, Talic YF. Designs of bond strength tests for metal-ceramic complexes: review of the literature. J Prosthet Dent. 1996;75(6):602-8.

33. Henriques B, Faria S, Soares D, Silva FS. Hot pressing effect on the shear bond strength of dental porcelain to CoCrMoSi alloy substrates with different surface treatments. Mater Sci Eng C. 2013;33(1):557-63.

34. Ekren O, Ozkomur A, Ucar Y. Effect of layered manufacturing techniques, alloy powders, and layer thickness on metal-ceramic bond strength. J Prosthet Dent. 2018;119(3):481-7.

35. Wiedenmann F, Klören M, Edelhoff D, Stawarczyk B. Bond strength of CAD-CAM and conventional veneering materials to different frameworks. J Prosthet Dent. 2021;125(4):664-73.

36. Tulga A. Effect of annealing procedure on the bonding of ceramic to cobalt-chromium alloys fabricated by rapid prototyping. $\mathrm{J}$ Prosthet Dent. 2018;119(4):643-9.

37. Dimitriadis K, Spyropoulos K, Papadopoulos T. Metal-ceramic bond strength between a feldspathic porcelain and a $\mathrm{Co}-\mathrm{Cr}$ alloy fabricated with direct metal laser sintering technique. $\mathrm{J}$ Adv Prosthodont. 2018;10(1):25-31. 